\title{
Diversity in burrow architecture of Laomedia spp. with habitat characteristics in the intertidal sediments of Korea
}

\author{
BON JOO KOO ${ }^{1,2 *}$ AND JAEHWAN SEO ${ }^{1,2}$
}

${ }^{1}$ School of Ocean Science, University of Science and Technology, Daejeon 34113, Republic of Korea

${ }^{2}$ Marine Ecosystem Research Center, Korea Institute of Ocean Science and Technology, Busan 49111, Republic of Korea ( ${ }^{*}$ Correspondence: B.J. Koo, bjkoo@kiost.ac.kr)

This study was designed to evaluate differences in burrow architecture of Laomedia spp. by habitat characteristics. The burrow casts were obtained from in situ resin casting in Saemangeum (SG, $\mathrm{n}=1$ ), Gomso (GS, $\mathrm{n}=5$ ), Namhae $(\mathrm{NH}$, $\mathrm{n}=5$ ) and Changseon (CS, n=4) tidal flats, respcetively, and the burrow architecture at each tidal flat was analyzed by $3 \mathrm{D}$ burrow model. The differences in burrow architecture by habitat characteristics were evaluated based on morphometric dimension and environmental factors such as sedimentary facies and exposure time. The habitat characteristics with respect to sedimentary facies and exposure time in SG and GS tidal flats differed from NH and CS tidal flats. The mean grain size was much finer in SG and GS tidal flats than in $\mathrm{NH}$ and CS tidal flats and exposure time was much longer in the former than in the latter. The burrows of Laomedia spp. in SG and GS tidal flats were divided into three parts. The upper part consists of a horizontal gallery and a vertical shaft connected to the surface of the tidal flat. The several horizontal passages are connected to the main gallery to form the middle part. The main gallery is inclined, spirally twisted, and extended downwards, and the direction of the twist is periodically reversed. The large chamber and small chamber are always paired at the direction changing point in SG tidal flat, while there is only small one in GS tidal flat. In NH and CS tidal flats, the upper part architecture is similar with SG and GS tidal flats, but the middle and lower parts of burrow is indistinct. The number of twist in the main gallery and the chamber size were relatively small compared to those of SG and GS tidal flats. The burrow size and morphometric dimensions in $\mathrm{NH}$ and $\mathrm{CS}$ tidal flats were smaller than in SG and GS tidal flats and the burrow architecture was simpler in the former than in the latter. These findings suggests that species and habitat characteristics is important factors in determining the burrow architecture and morphometric dimensions of Laomedia spp. However, the species classification should be conducted in order to evaluate the species-specific differences in the burrow architecture of Laomedia spp. 